\title{
Improving Student Engagement in Higher Education through Mobile-Based Interactive Teaching Model Using Socrative
}

\author{
Woan Ning Lim \\ Department of Computing and Information Systems \\ School of Science and Technology, Sunway University \\ Bandar Sunway, Malaysia \\ woanningl@sunway.edu.my
}

\begin{abstract}
One of the main problem in higher education teaching is low students' levels of engagement leading to poor learning performance. Broad teaching strategies, methods and tools are developed over the years to address this concern. In recent years, with the increasing numbers of students accessing the internet using mobile devices, there has been growing interest in embracing the mobile technology in teaching to improve the student participation in the classroom. This research describes the design and implementation of a mobile-based interactive teaching model with in-class and off-class components aided by Socrative online audience response system to improve students' engagement in a private university in Malaysia. A total of 45 students from undergraduate computing course had participated in this experimental study. The activities such as polls, exercises, quizzes and games was used to stimulate the discussion and encourage two ways communication between instructor and students. Both qualitative and quantitative data comprises of students' feedbacks, academic results, attendance records and instructor's teaching evaluation scores are analyzed. The results show that students were strongly positive with the use of Socrative and felt that they were more engaged. This interactive model has successfully enhanced students' learning experience and improved students' academic performance. The outcome of this study would contributes to current evidence of the efficacy of using mobile technology in higher education teaching.
\end{abstract}

Keywords-interactive teaching model; student engagement; mobile teaching tool; mobile learning

\section{INTRODUCTION}

Improving students' engagement is a challenge faced by many institutions in the higher education sector. Many pedagogical researchers believe that low engagement in classroom will lead to negative impact in achieving the learning outcome, hence tremendous efforts and focus have been put in this research area over the decades [1].

The problem with today's education is that most educators are still teaching the way they were taught in the past, as quoted by John Dewey "if we teach today as we taught yesterday, we rob our children of tomorrow". The one-way communication of standard lecture and PowerPoint presentations in the old days no longer effective in encourage learning. Two ways communication is the sought after approach in various education researches nowadays to address the problem in low students' engagement. Students are motivated to engage in the classroom when they know that they are heard by the instructor. Hence it is essential to explore new ways from traditional teaching to improve the bonding between instructor and students in this technology-rich $21^{\text {st }}$ century.

New technological innovations have often been attributed with the potential to have a large impact on the field of education. Mobile technology has evolved rapidly with the decrease in cost of ownership and enhancement in userfriendliness, resulted in the vital increase of mobile devices adoption rate amongst higher education students over the years. Majority students agreed that mobile devices will transform the way they learn in the future and make learning more fun [2]. Furthermore, the higher education environments are getting matured to adapt the mobile technologies with the readiness of WiFi coverage across the campus. These made the integration of such technology into the classroom more feasible compared to early years. Engaging these 'millennial' generation or digital natives using the technologies they are familiar with their own devices which are stapled to their daily lives is certainly welcoming. The concept of using personal mobile devices in education settings for in-class interactive activity is aligned with the new trend coined as Bring Your Own Device (BYOD) or Bring Your Own Technology (BYOT) [3][4].

In this research, an interactive teaching model assisted with mobile technology is experimented to enhance the interactions and feedbacks between instructor and students, with the aim to engage students in their learning.

\section{RELATED WORK}

In the past, before the common use of mobile technology in education, one way of gaining immediate feedback during classroom instruction is to employ clicker, a radio frequencybased electronic feedback devices. Clicker is a small portable device that uses infrared or radio frequency technology to transmit and record students' responses to questions. The use of clickers has revealed a variety of benefits with regard to the instantaneous feedback to both the instructor and students, the anonymity of the responses encourages the participation of students who may otherwise be reluctant to do so [5]. Research 
study showed an outstanding improvement in the communicative competence of students with the use of clickers [6]. The use of clickers has also indicated an increase in student participation in class and the regression results showed that the use of clickers had positive and significant impact on students' academic performance [7][8]. However, students from a private college in United States disagreed or were neutral with the above statement [9]. Hence, the argument of better student engagement leads to the improvement of grades remains debatable.

Recent years, majority researches are into investigating the usage of online audience response system in effective teaching [10][11][12]. Most of the online audience response systems embrace the Cloud technology and are supported on any webenabled devices including laptops, iPads, Android tablets and mobile phones which can also be installed as native application on the mobile devices. It is an easy to use tool with minimum setup footprint while negating some of the limitations of clickers such as device purchasing costs (students can run the online tool on their own mobile devices). An experimental study with the comparison of both clickers and online audience response system confirmed the same positive effect in student engagement, with favorable experiences on the latter, reported by most instructors [5].

Poll Everywhere claimed to be the first audience response tool for mobile devices [13]. It is a simple application that works well for live audiences to response via the web, text messages, or twitter through their phones. The free plan is offered with limitation of 25 responses per poll and paid plans without any restrictions. Research result revealed strong positive responses of using Poll Everywhere in a large introductory computer science course with 291 students, as well as a small classroom of 30 students, where mobile phones were the most popular device that students used in answering the polling, followed by laptops and iPads[14][12]. Students who attended lecture enjoyed using Poll Everywhere and felt they were more engaged. However, the use of this interactive pedagogy did not show direct positive influence in student attendance[14].

Socrative is another cloud based audience response system that has gained popularity amongst educators in view of the drawback of Poll Everywhere in limiting the number of responses for their free plan. As of 2013, Socrative has recorded a strong growth with total of 450,000 registered members and more than 40,000 new registration each month [15]. Socrative was developed in 2011 by a Boston-based start-up. It is a free service (with paid option for additional features) that allows instructors to gather timely response from students in the form of multiple choice, true/false, or short answers and to handle inclass polling, off-class pooling or formative assessment. Socrative is also equipped with gamification feature for running a quick quiz game. The service is available across platforms and devices (laptops, tablets, and/or smartphones) provide the ease for instructors to engage students and gather feedback by harnessing the mobile technologies that students bring to class.

The researches using Socrative to enhance teaching in higher education have been continuously growing over the past few years. Many have indicated positive acceptance level of students and/or instructors toward the use of this technology in improving students in-class participation [16][17][18]. A response of $96 \%$ agreed on the ease of use and $92 \%$ on improving the engagement were reported in the research study involved sixty-five 1st year university students where Socrative was used in getting students' responses during lectures and delivering prepared quizzes in tutorials [10]. One significant advantage highlighted in the report was the tool allows quieter students to interact with instructor without the fear of making 'public' mistakes. There is another study indicated a statistically positive relationships between the variables (participating, collaborate, discuss, extend and grow as a community) and performance of students in Irbid National University after the used of Socrative [19].

In the researches cited above, it is observed that the online audience response system was mainly used to handle simple inclass activities such as polls and quizzes, there is lack of discussions on the design or establishment of any teaching model. Hence, this research is motivated to introduce an interactive teaching model comprises of in-class and off-class components aided by Socrative to empirically investigate some of the findings from the researches above. The effectiveness of this model in improving students' engagement is evaluated in this study.

\section{IMPLEMENTATION}

The experiment was carried out in an undergraduate programming class from March to July 2016 and involved a total of 45 students from the Information Technology programme in Sunway University. In this study, the interactive teaching model was implemented in the lecture class once per week for a continuous of 14 weeks. Both qualitative and quantitative data were collected in the research. Survey questionnaires were conducted online anonymously to evaluate participants' involvement and perception, while students' academic results, attendance records and the instructor's teaching evaluation scores from the experiment were extracted and compared with past year data. The implementation platform, model design and activities details are discussed in the following sections.

\section{A. Platform}

A free version of Socrative was used in this study. It composed of two main modules, which are Socrative Student and Socrative Teacher modules. The teacher module allows instructor to prepare and manage quizzes, run polls and view reports. The student module is a simpler module for students to participate in the activities. It can run on multi platforms either on an internet connected web browser or can be installed as native application on any mobile devices. Socrative offers the flexibility and ease of use by eliminating the needs for students to create account, they can join a virtual classroom via a room code created by the instructor without prior registration.

\section{B. Interactive Teaching Model}

The experimented interactive teaching model is shown in Fig. 1. It incorporates both in-class and off-class components to increase students' engagement by encouraging students' responses (before and during the class), providing timely assessment feedback, and implementing gamification in learning. 
Off-class

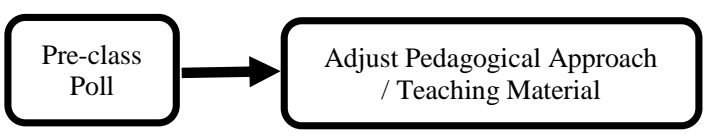

In-class

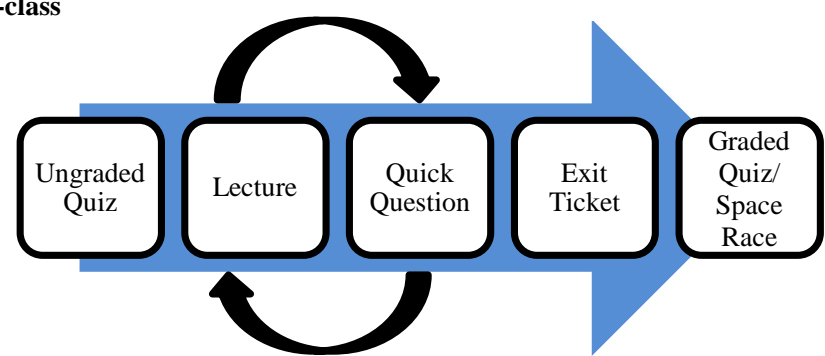

Fig. 1. Interactive teaching model with in-class and off-class components

The interactive model emphasizes on two main aspects which are rapid feedback and formative assessment. This is supported by the research findings that rapid feedback has the potential to enhance student learning and formative assessment can inform instructor about their students' understandings of concepts and thus provide instructor with information to adapt different teaching practices [20].

The off-class component consists of pre-class poll which allows students to prepare and provide feedback before class commences. The feedbacks will assist the instructor to implement Just-in-Time Teaching (JiTT) by fine-tuning the lecture materials or classroom activities to best meet students' needs. This can increase the effectiveness of learning during classroom time and encourage students to prepare before class.

Existing research and study claimed that students' concentration declines after 10 to $15 \mathrm{~min}$ into lectures [21]. Hence, the in-class model is designed with intersection of teaching and various interactive activities such as quizzes, polls, exit tickets and space races in order to achieve the goal of maximizing students' attention and participation in the class.

Quick question can run multiple times during the lecture and exit ticket is a quick poll that run once at the end of the lecture to capture student feedbacks. The quick questions and exit tickets allow students to feedback anonymously on the teaching effectiveness (i.e. presentation style, teaching pace, pedagogical method) or the topics to be reiterated. With this, the instructor not only knowing the thinking and learning performances of a small part of students in class where most of the students neither reveal their doubts nor answer the questions that the instructor formulated publicly, but also hearing broader opinions especially in a big classroom setting. This can improve learning effectiveness with teaching adjusted to the needs of students, and further enhance student motivation to participate as they know their voices are heard.

A few research studies mentioned that quizzes as formative assessment can better engage students in their learning [22][23]. A quiz overlapping strategy with graded and ungraded quiz is applied in this model. Ungraded quiz is used as reading quiz before lecture commence, whereas graded quiz is used as formative assessment at the end of the lecture to evaluate students' learning outcome. With the aid of Socrative, instructor can handle in-class quizzes and give students immediate feedbacks on the answers and grades to regulate their learning.

Space race is a quiz-based game used interchangeably with the graded quiz for better learning experience. Although graded quiz can provide more precise evaluation of students' performance, space race is vital in engaging the students by making learning more enjoyable. Researches revealed that gamification in learning can motivate and attract students to learn [24][25]. The combination of mobile learning and gamebased learning approaches offer possibilities to promote the engagement of university students [26].

\section{Activities}

Preparation. Instructor was required to register for a Socrative teacher account to be used throughout the experiment. Upon the account creation, a virtual classroom was automatically setup and assigned with a unique name, which could be changed by the instructor from the teacher module. In this experiment, the subject code was used as the room name for easy access.

Before the class commenced, a set of multiple choice and true/false questions related to the lecture topic for that particular day were prepared and uploaded to Socrative. There were multiple ways to upload the questions to Socrative. The questions could be created in real-time by logging into the online teaching module, imported from an offline Excel file or extracted from the repository. Amongst the available methods, preparing the questions in offline Excel file was recommended. Excel file provided flexibility in making addition and amendment, and could be kept as a secondary backup. To use this method, instructor had to download the Excel template from Socrative, populate the questions and answers, then import it to Socrative by clicking the Import Quiz button from the teacher module.

Despite the convenience and flexibility, this method had a drawback. The Excel template could not support true/false question, a workaround by converting a true/false question into multiple choice question with only two choices (i.e. True and False) was used. Although short answer question was supported, it was not advisable to be used in any graded assessment due to the lack of intelligent matching algorithm in Socrative, any correct answers but worded differently would be incorrectly assessed.

Pre-class poll. Pre-class poll was launched two days before the class to gain insight into students' understanding and expectation for the coming lecture. Students were asked to study the teaching materials beforehand and a follow up poll was carried out with some of the common questions such as 'list three important concepts in the module', 'vote for the toughness level of each submodule', or a simple task for students to find the answer from the lecture slides. This pre-class poll provided sufficient time for instructor to adjust the teaching material in response to the feedbacks before the class commenced.

Ungraded quiz. Questions of ungraded quiz were composed from half of the graded quiz questions related to the lecture topics. Ungraded quiz was launched for a short 10 minutes at the beginning of lecture as reading quiz, with the settings of student 
paced navigation, disable student results and disable student names as shown in Fig. 2.

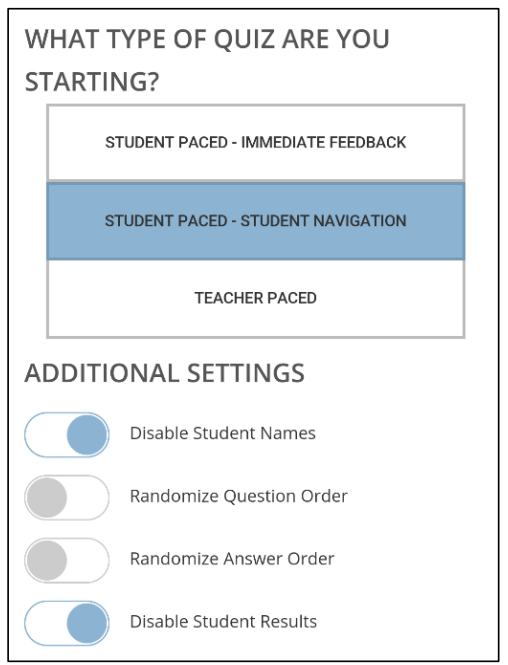

Fig. 2. Ungraded quiz settings

The student paced navigation setting allowed students to skip questions or navigate forward and backward through the quiz in their own way, and submitted the entire assessment once they had completed the activity. This activity was not a graded assessment; hence it was neither needed to collect students' name nor notify the students of their grades. The intention of this ungraded quiz was to estimate the students' comprehensions and understanding of the topic, at the same time entice the student to stay focus and be more engaged to find the answer for the graded Quiz. Furthermore, the ungraded quiz provided a good overview regards the topics to be covered and encouraged students to ask questions and clarify any doubts during the lecture.

Quick question. The quick question was usually carried out in two phases. Short question was launched for 1-2 minutes after the explanation of a subtopic during the lecture to collect the feedbacks from students, sample snapshot is shown in Fig. 3.

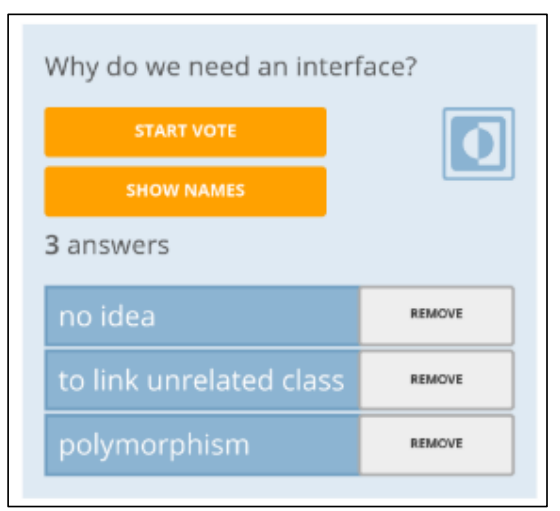

Fig. 3. Sample Socrative teacher's view with students' answers

Followed by the instructor triggering the voting process for students to vote on the collected answers. Instructor usually removed the duplicate answer before the voting. The votes were displayed in real-time in the Socrative teacher module, sample screenshot is shown in Fig. 4.

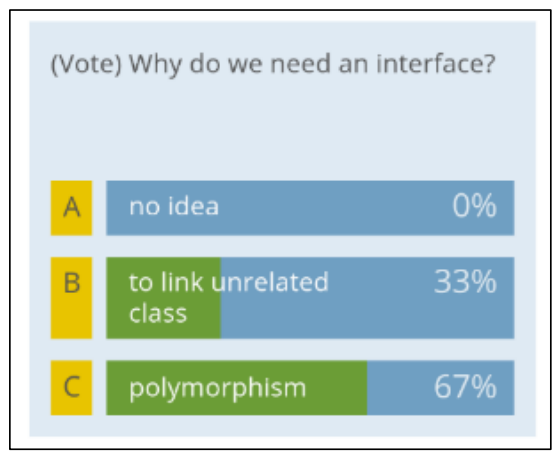

Fig. 4. Sample Socrative teacher's view with students' votes

Short answer question was preferable in this activity instead of multiple choice question to encourage active thinking. This activity could be triggered as frequently as necessary during the lecture. It provided immediate feedback to instructor regarding the students' understanding on the taught concepts, hence allowed the instructor to adjust the teaching pace or revisit a certain topic accordingly.

Exit ticket. Exit Ticket was a quick way for instructor to gather summative feedback and mainly triggered at the end of the class. This activity provided students a chance to reflect what they had learnt, voice up their concerns, or raise red flag. It gave instructor a good snapshot of the students' progress and attitude towards the class. This helped instructor to adjust the following day's lesson and teaching accordingly.

The exit ticket activity consisted of three common questions that could not be altered. The first question was "How well did you understand today's material?", the second question was "What did you learn in today's class?" and the third question was "Please answer the teacher's question". The last question allowed instructor to ask customize question by projecting out in the classroom for student to answer. The customize questions that most frequently asked are 'What questions or concerns do you have about today's lecture', 'Which topic you like the most' or 'Write one question about today's lesson that has left you puzzled'.

This activity was extremely helpful to provide broader feedbacks to the instructor, as most of the students were always shy away when instructor verbally asked in the class which resulted in a false impression that the lectures were progressing well.

Graded quiz. A graded quiz normally consisted of 20 questions and was given at the last 15-20 minutes of the class as formative assessment to evaluate students' learning. The quiz was launched with the settings of student immediate feedback navigation, randomize question order, randomize answer order and disable student feedback as shown in Fig. 5.

The student immediate feedback navigation setting disallowed backward navigation, while the randomization setting enforced different question and answer sequence. This combination was effective in minimizing the plagiarism especially in a non-exam venue where students were sitting next to each other; students had little chance to plagiarize within the limited time. 


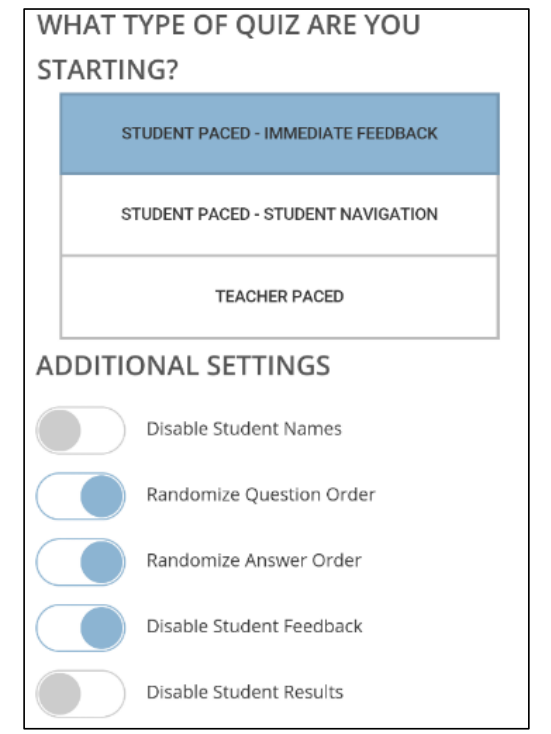

Fig. 5. Graded quiz settings

During the quiz, students' progress and scores could be monitored via the dashboard in real-time which enable instructor to have a better control. Various reports were generated after the quiz completion for analysis purposes. Three report types available in Socrative were Whole Class Excel, Individual Student(s) PDF and Question Specific PDF. The Whole Class Excel report provided an overview of the class performance with the information of students' marks and the scores of each question. This format was usually used by instructor to publish the results for students' reference. The Individual Student(s) PDF was not particularly useful, as most of the information can be obtained from the Whole Class Excel report, hence this format was not used in this experiment. The Question Specific PDF was an important report used by the instructor as revision with the class immediately after the quiz. This report displayed the answer and the correct ratio of each answer choice. It was useful in analyzing each question difficulty level and to identify the questions that required further explanation.

In this experiment, the revision after the quiz had successfully drawn the students' attention and improved the class participation. Every student eagerly wanted to know the correct answer and to check if others had made the same mistakes. This is aligned with the research findings which claimed that by making assessment feedback more accessible, students are more likely to engage with it and this will have a beneficial impact on their learning [27].

Space race. Space race was a quiz-based game used as an alternative to graded quiz in this experiment. Both components were used interchangeably for better learning results. In this activity, quizzes were deployed as fast-paced rocket race game to track the students' performance. Students could participate in the space race by pairs or small groups. During the game, each correct answer moved the rocket one step across the screen as shown in Fig. 6 and the team with most questions correctly answered would win the space race. In this experiment, students were grouped in five per team to achieve optimum groups with manageable number of members.

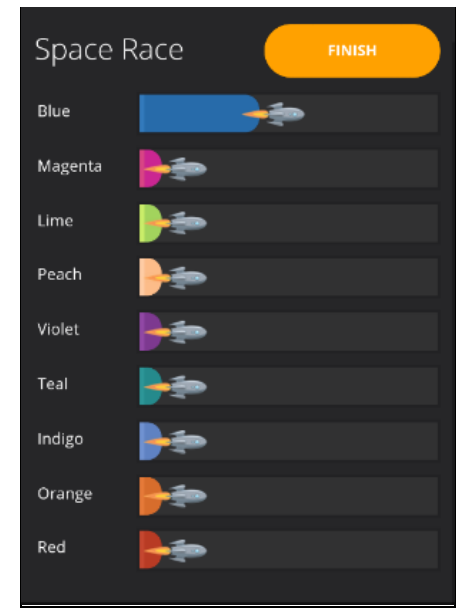

Fig. 6. Sample space race result snapshot

This activity meant to encourage engagement through team works, so the marks were equally honored to each team members. Students had shown great interest in this activity and were actively participated in the team discussion during the game.

\section{RESUlts}

The analysis of this study is based on the qualitative data collected from the students' survey questionnaire and instructor's teaching evaluation scores, complemented with quantitative data of students' academic results and attendance records.

\section{A. Students' Survey}

Survey was conducted online anonymously at the end of the semester where students were asked to fill-up a questionnaire consists of total 9 questions. Questions 1-4 evaluate the impact of engagement, questions 5-6 assess the acceptance of the teaching tool, question 7-8 evaluate the tool as assessment engine and the last open question to capture any additional comments from the students. The questions are as per listed in TABLE I. This survey has obtained $84 \%$ response rate with 38 out of 45 students took part in the survey.

\section{TABLE I. SURVEY QUESTIONS}

\begin{tabular}{ll}
\hline Q1 & $\begin{array}{l}\text { My learning experience of using the Socrative tool in } \\
\text { the classroom is good. }\end{array}$ \\
\hline Q2 & The usage of Socrative tool able to motivate me in my learning. \\
\hline Q3 & $\begin{array}{l}\text { The usage of Socrative tool encourage me to stay focus in the } \\
\text { classroom. }\end{array}$ \\
\hline Q4 & Socrative tool able to enhance my engagement with the lecturer. \\
\hline Q5 & $\begin{array}{l}\text { Overall, I am satisfied with the usage of Socrative tool in } \\
\text { my classroom. }\end{array}$ \\
\hline Q6 & $\begin{array}{l}\text { I am likely to recommend other lecturers or friends to use the } \\
\text { Socrative tool. }\end{array}$ \\
\hline Q7 & $\begin{array}{l}\text { If you are to recommend the Socrative tool, you prefer it to be used } \\
\text { as: }\end{array}$ \\
\hline Q8 & $\begin{array}{l}\text { If you are to take this subject again, which assessment components } \\
\text { do you prefer to have higher mark weightage? }\end{array}$ \\
\hline Q9 & \begin{tabular}{l} 
Any other comments? \\
\hline
\end{tabular}
\end{tabular}


Five-point Likert scale is used in Q1-Q6, with 1 as 'Strongly Disagree' and 5 as 'Strongly Agree'. A summary of the findings, the means, standard deviations and skewness are listed in TABLE II and Fig. 7.

TABLE II. RESULTS OF THE STUDENTS' SURVEY

\begin{tabular}{lcccccc}
\hline & Q1 & Q2 & Q3 & Q4 & Q5 & Q6 \\
\hline $\mathbf{N}$ & 38 & 38 & 38 & 38 & 38 & 38 \\
Mean & 4.3684 & 4.1579 & 4.3421 & 4.2632 & 4.5789 & 4.2895 \\
Std. & & & & & & \\
Deviation & 0.5891 & 0.7893 & 0.7081 & 0.6445 & 0.5517 & 0.7679 \\
Skewness & -0.2922 & -0.2941 & -0.6076 & -0.3011 & -0.8385 & -0.5587 \\
\hline
\end{tabular}

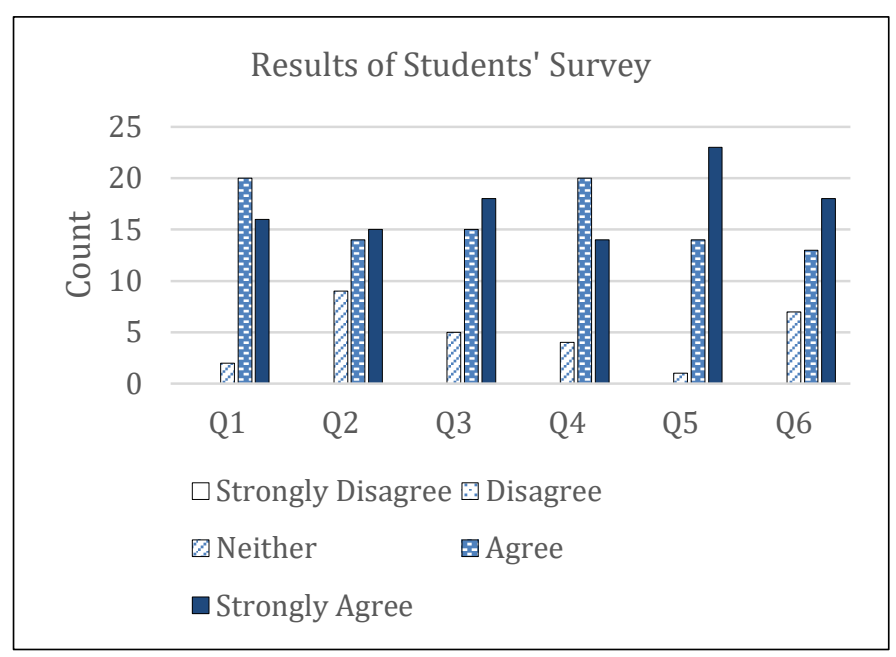

Fig. 7. Results of students' survey

In general, students had responded positively in the survey. It is observed that the bars are sided to the right side of the graph (Fig. 7) which indicates that most of the students responded between strongly agree and agree while none disagreed to any of the questions. The mean and skewness of Q1-Q4 shows that students had a good learning experience with Socrative and agreed that their focus in the class and their engagement with the lecturer had improved. The main driver that kept the students staying alert was the impromptu quick questions and quizzes, which had motivated students to clarify any doubts during the lecture in order to achieve better scores in the assessment. The less agreed point is Q2 with bigger standard deviation at 0.7893 and lower mean at 4.1579 where some students stayed neutral about the effectiveness of Socrative in motivating their learning. The findings above lead to $1^{\text {st }}$ conclusion: The implementation of mobile-based teaching model using Socrative does enhance the students' learning experience and their engagement with the instructor.

Result of Q5 indicates that students were satisfied with the usage of Socrative in the class with the smaller standard deviation at 0.5517 and highest mean at 4.5789. Most of the students were very likely to recommend the others to use the tool as supported by the result in Q6. This confirms the $2^{\text {nd }}$ conclusion: Socrative is highly accepted by student as teaching aided tool.
In this experiment, Socrative was used to handle the ungraded and graded quiz in class. It is crucial to evaluate the students' acceptance on the adoption of mobile technology in assessment handling. Survey results of Q7 and Q8 are analyzed and shown in Fig. 8.

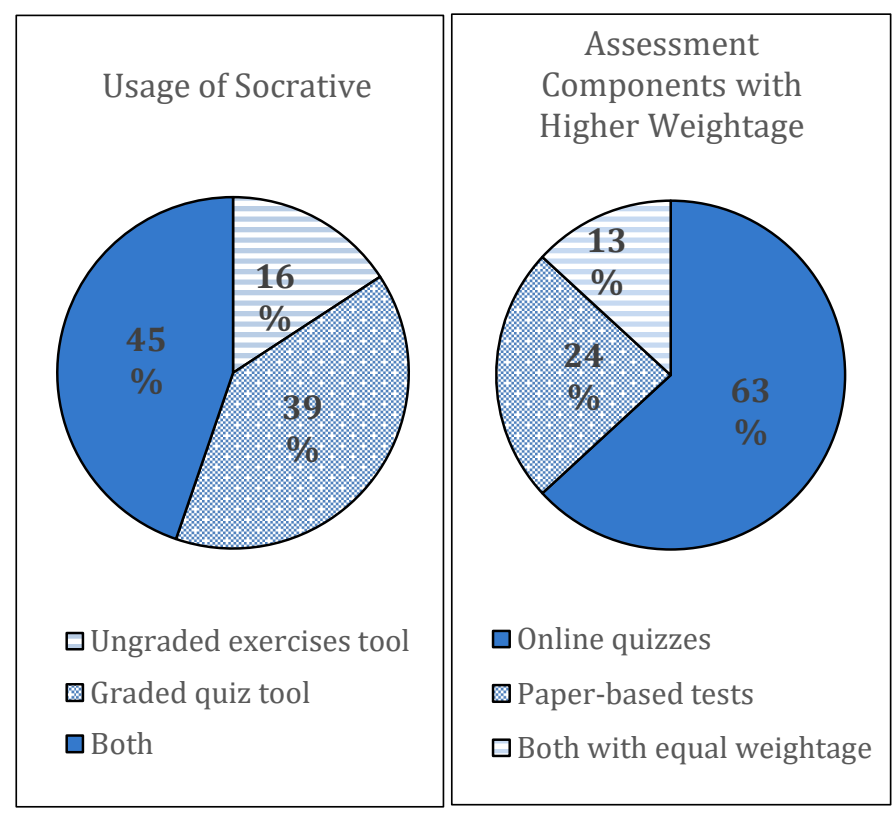

Fig. 8. Survey results of Socrative usage and assessment components with higher weightage

The results indicate that majority of the students at $84 \%$ welcomed the usage of Socrative as graded quiz tool. And, 63\% of the students voted for higher assessment weightage in online quizzes over the paper-based tests. From the findings, $3^{\text {rd }}$ conclusion is drawn: Socrative is highly accepted by students as formative assessment tool.

The high acceptance is not surprise in view of Socrative able to provide instant feedbacks and answers to the students, which is lacking from the paper-based assessment, a disjointed process involving staff marking manually and students collecting marked papers at a later time. Researches showed that students most value the feedback which they can use immediately to improve an assessment mark [28]. The online publication of results and feedback and the adaptive release of grades were found to significantly enhance students' engagement [29].

The last question in the survey is an open question to gather the opinions, comments and concerns regarding the usage of Socrative in the classroom. Generally, students responded with positive comments such as 'Socrative is an excellent tool', 'it is a great platform', 'it allows me to give feedback easily' etc. One of the highlighted response is 'Socrative is fun', this supported the aim of mobile-based teaching where the fun element in the modern technology is an important factor to enhance students' engagement in their learning.

\section{B. Academic Results}

The academic result is a crucial element to be examined in the hypothesis of better students' engagement leads to better academic performance. Past year results are adopted for 
comparison in consideration of identical class settings such as class size (45 students), instructor, syllabus and assessment arrangements. The academic results of the students who participated in this experiment (year 2016) and the past year results (year 2015) are analyzed based on three major components (i.e. quizzes, project and exam) as shown in Fig. 9 and Fig. 10.

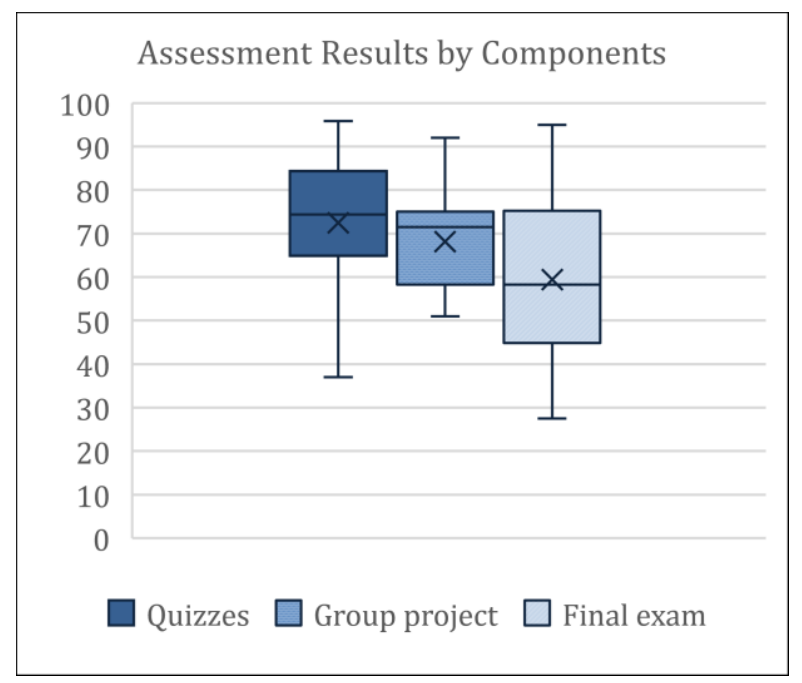

Fig. 9. Assessment results by components

Results in Fig. 9 show that quizzes have higher mean compared to project and exam. This finding can relate to the discussion in Section A - Students' Survey, where students strongly voted for online graded quizzes and prefer higher weightage over the paper-based tests. One influencing factor that causes better students' performance in the quizzes is the instantaneous feedbacks that instructor received during the lecture, which allows the topics in doubt to be reiterated right away.

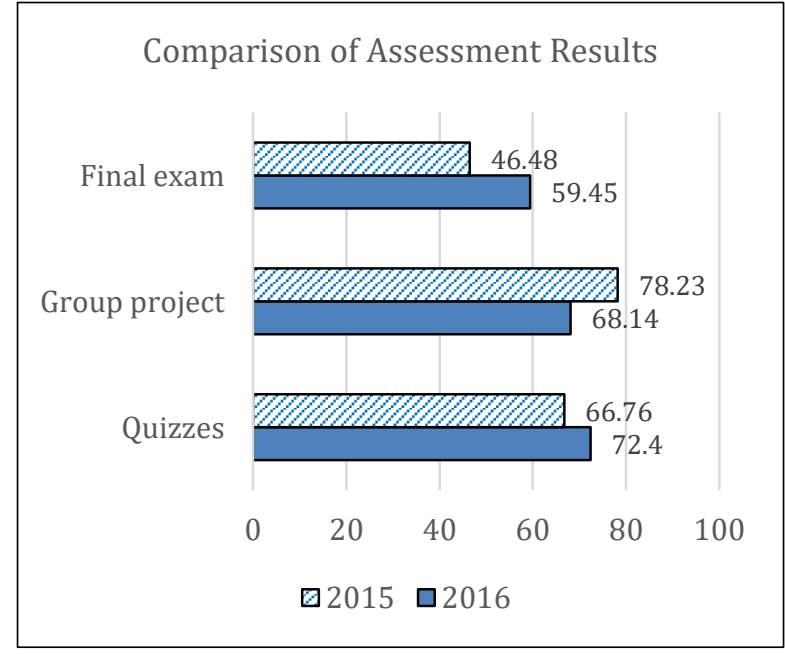

Fig. 10. Comparison of assessment results

As seen from the results in Fig. 10, students' performance in quizzes and exam are significantly improved upon the implementation of Socrative from $66.76 \%$ in 2015 to $72.4 \%$ in 2016, and from $46.48 \%$ in 2015 to $59.45 \%$ in 2016 respectively. However, weakening result is observed in the group project.
This finding is not a surprise in view of many students feed backed that they felt more difficult in connecting directly the project work with the in-class learning. Indeed, those tasks where aiming at different kind of competences development. The nature of project is a less engaging task in classroom; but a group work which required more self-learning, team works, leadership and peer discussion. The tasks in a project tend to be challenging and the learning outcome is to derive and apply the theories learnt. It is observed that the implementation of interactive teaching model alone is not sufficient, it should be complemented with peer discussion platforms and project management tools. Hence, the $4^{\text {th }}$ conclusion is drawn: Mobilebased teaching model using Socrative does improve students' test performance but not project work.

\section{Attendance Records}

Attendance records of the participants are compared with the past year attendance records in view of the resemblance in both class settings. The average at $85 \%$ attendance in year 2016 has shown a minor drop against the average at $90 \%$ in year 2015 . The finding shows that students were not positively influenced to come to lecture although students who attended lecture enjoyed the class and felt they were more engaged. This leads to the $5^{\text {th }}$ conclusion: The implementation of mobile-based interactive teaching model does not improve students' attendance.

When checking the correlation between the attendance performance and academic results with the multivariate linear regression analysis with Pearson correlation coefficient, it is observed that a significant correlation is found at $r(42)=.53$, $\mathrm{p}<.001$ as listed in TABLE III. Since students who attended the lecture claimed that they were more engaged as per discussed in Section A - Students' Survey, this supports the hypothesis of better students' engagement leads to better academic performance.

TABLE III. MULTIVARIATE LINEAR REGRESSION ANALYSIS OF ATTENDANCE RECORDS AND ACADEMIC RESULTS

\begin{tabular}{lr}
\hline \multicolumn{2}{c}{ Regression Statistics } \\
\hline Multiple R & $\mathbf{0 . 5 2 6 6}$ \\
R Square & 0.2773 \\
Adjusted R Square & 0.2601 \\
Standard Error & 13.8322 \\
Observations & 44 \\
\hline
\end{tabular}

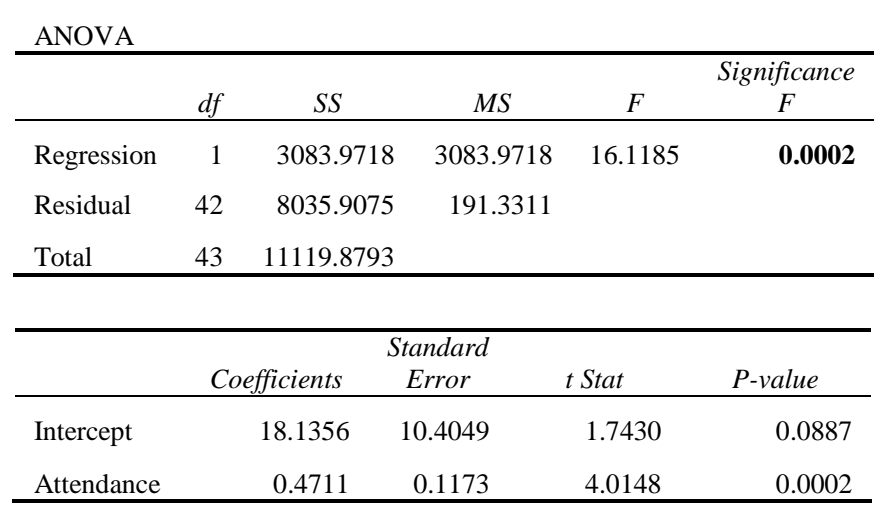




\section{Teaching Evaluation Scores}

The levels of student engagement are highly influenced by the students' appreciation levels of the teaching. In Sunway University, students are required to participate in the teaching evaluation for every subject they enroll. The survey comprises of 15 questions, with 8 questions on subject evaluation and 7 questions on teaching appreciation. This evaluation activity is carried out anonymously at university level in every semester. The teaching evaluation scores for the programing class involved in this research are listed in TABLE IV.

TABLE IV. TEACHING EVALUATION RESULTS

\begin{tabular}{|c|c|c|c|c|}
\hline & & 2015 & $2016^{\mathrm{a}}$ & Diff \\
\hline & & $\%$ & $\%$ & $\%$ \\
\hline & Mean & 77.5 & 91.4 & 13.9 \\
\hline \multicolumn{5}{|c|}{ SUBJECT } \\
\hline Q1 & $\begin{array}{l}\text { I had a clear understanding } \\
\text { of the aims and goals of } \\
\text { this subject }\end{array}$ & 81.0 & 92.0 & 11.0 \\
\hline Q2 & $\begin{array}{l}\text { The subject was well- } \\
\text { structured }\end{array}$ & 78.0 & 90.0 & 12.0 \\
\hline Q3 & $\begin{array}{l}\text { The subject enabled me to } \\
\text { achieve the learning } \\
\text { outcomes }\end{array}$ & 77.0 & 93.0 & 16.0 \\
\hline Q4 & $\begin{array}{l}\text { The subject was } \\
\text { intellectually stimulating. } \\
\text { (That is, it made me think) }\end{array}$ & 80.0 & 91.0 & 11.0 \\
\hline Q5 & $\begin{array}{l}\text { The subject developed my } \\
\text { problem solving skills }\end{array}$ & 77.0 & 90.0 & 13.0 \\
\hline Q6 & $\begin{array}{l}\text { The learning resources } \\
\text { assisted my learning in } \\
\text { this subject }\end{array}$ & 74.0 & 90.0 & 16.0 \\
\hline Q7 & $\begin{array}{l}\text { When I enquired, I } \\
\text { received helpful feedback } \\
\text { on my progress in the } \\
\text { subject }\end{array}$ & 77.0 & 93.0 & 16.0 \\
\hline \multirow[t]{2}{*}{ Q8 } & $\begin{array}{l}\text { Overall, I am satisfied } \\
\text { with the quality of this } \\
\text { subject }\end{array}$ & 79.0 & 92.0 & 13.0 \\
\hline & TEACHING & & & \\
\hline Q9 & $\begin{array}{l}\text { The lecturer was well } \\
\text { organized }\end{array}$ & 79.0 & 92.0 & 13.0 \\
\hline Q10 & $\begin{array}{l}\text { The lecturer's } \\
\text { explanations helped my } \\
\text { understanding }\end{array}$ & 75.0 & 93.0 & 18.0 \\
\hline Q11 & $\begin{array}{l}\text { The lecturer inspired me to } \\
\text { learn }\end{array}$ & 72.0 & 92.0 & 20.0 \\
\hline Q12 & $\begin{array}{l}\text { The lecturer encouraged } \\
\text { students to be involved in } \\
\text { their learning }\end{array}$ & 78.0 & 93.0 & 15.0 \\
\hline Q13 & $\begin{array}{l}\text { The lecturer encouraged } \\
\text { me to participate }\end{array}$ & 75.0 & 89.0 & 14.0 \\
\hline Q14 & $\begin{array}{l}\text { My marked assignments } \\
\text { were returned within the } \\
\text { stipulated time }\end{array}$ & 82.0 & 91.0 & 9.0 \\
\hline Q15 & $\begin{array}{l}\text { Overall, the lecturer was } \\
\text { excellent }\end{array}$ & 78.0 & 90.0 & 12.0 \\
\hline
\end{tabular}

Five-point Likert scale is used in the survey and the satisfaction percentage is calculated based on $0 \%$ as 'Strongly Disagree' and $100 \%$ as 'Strongly Agree'. Significant improvement is observed at the mean $91.4 \%$ in year 2016 compared to $77.5 \%$ in year 2015 . This indicates that students were more satisfied with the overall quality delivered by the instructor in year 2016. This leads to the $6^{\text {th }}$ conclusion: Students' satisfaction of the subject and teaching quality are greatly improved with the implementation of mobile-based interactive teaching model

Strong positive readings at 93\% in Q3 'The subject enabled me to achieve the learning outcomes', Q7 'When I enquired, I received helpful feedback on my progress in the subject', Q10 'The lecturer's explanations helped my understanding' and Q12 'The lecturer encouraged students to be involved in their learning' show that students' learning experience had improved with the real-time feedback mechanism implemented in the classroom; students felt more in control of their studies with the ease and comfort of the feedback channel hence encourage them to be more involved in their learning. The positive readings confirm that mobile-based interactive teaching model is effective in enhancing the interactions between instructor and students which leads to better students' engagement in their learning.

\section{CONClusion}

Generally, the feedbacks received in this study are positive. The implementation of mobile-based interactive teaching model does encourage the engagement and participation of students in class. Majority students agreed that their focus in the class and their bonding with the instructor were improved which greatly enhanced their learning experience.

Students and instructor have positive attitude about Socrative as the feedback and formative assessment tool. The cost-free and interactive features have added to the popularity of Socrative in the education sector.

Students' overall academic performance had improved especially in the test and exam components, but no positive influence is observed on project works. This agrees to the arguments that the nature of group project requires more team works and peer discussions, hence the needs of not only the interactive teaching, but implementation of peer discussion and project management assistance tools.

Statistically significant correlation is found between the students' attendance records and exam grades, however the mobile-based interactive teaching does not positively change the students' attendance behavior. This concludes that the students who attended the class felt engaged and able to score better but students who are a frequent absentee did not become motivated to attend the class.

Based on the findings and the experience in the classroom, this mobile-based interactive teaching model is recommended for instructors who are looking to integrate a quick feedback or active learning element to their classroom to better engage their audience. One aspect that can be looked into is the influence of 
bigger class size towards the effectiveness of this teaching model and the impact on the teaching and learning experience.

This research also reveals a high acceptance of mobile technology integrated pedagogy activities by higher education students in Malaysia

\section{REFERENCES}

[1] L. Taylor and J. Parsons, "Improving Student Engagement.," Curr. Issues Eudcation, vol. 14, no. 1, pp. 1-33, 2011.

[2] H. Poll, "Pearson student mobile device survey 2015," 2015.

[3] F. Onyechere Ugochukwu and M. Z. Ismail, "The future of BYOD in organizations and higher institution of learning," Int. Journals Accounting, Bus. Manag., vol. 1, no. 1, pp. 1-5, 2015.

[4] I. Pogar, M. Gligora, and V. Davidovi, "BYOD : a challenge for the future digital generation," in 36th International Convention on Information and Communication Technology, Electronics and Microelectronics, MIPRO 2013 - Proceedings, 2013, pp. 748-752.

[5] B. Martinez and H. Seli, "Just-in-Time or Plenty-of-Time teaching? Different electronic feedback devices and their effect on student engagement,” J. Educ. Technol. Soc., vol. 17, no. 2, pp. 234-244, 2014.

[6] A. O. Agbatogun, "Developing learners' second language communicative competence through active learning: Clickers or communicative approach?," Educ. Technol. Soc., vol. 17, no. 2, pp. 257-269, 2014.

[7] E. Bojinova and J. Oigara, "Teaching and learning with Clickers in higher education,” Int. J. Teach. Learn. High. Educ., vol. 25, no. 2, pp. 154-165, 2013.

[8] S. Simelane and A. Mji, "Impact of technology-engagement teaching strategy with the aid of Clickers on student's learning style," Procedia Soc. Behav. Sci., vol. 136, pp. 511-521, 2014.

[9] E. D. Bojinova and J. N. Oigara, "Teaching and learning with Clickers: Are Clickers good for students?," Interdiscip. J. E-Learning Learn. Objects, vol. 7, pp. 169-184, 2011.

[10] P. Dervan, "Increasing in-class student engagement using Socrative (an online student response system)," All Irel. J. Teach. Learn. High., vol. 6, no. 2, p. 1977,2014

[11] M. Kastner, "The use of an audience response system to monitor students' knowledge level in real-time, its impact on grades, and students' experiences," in Proceedings of the Annual Hawaii International Conference on System Sciences, 2016, no. March, pp. 104-113.

[12] T. Surentheran, "Use of an electronic voting system to facilitate interactive engagement and enhance active learning of undergraduate students in biomedical science," Investig. Univ. Teach. Learn., vol. 9, no. spring, pp. 111-121, 2014.

[13] "About Poll Everywhere." [Online]. Available: https://www.polleverywhere.com/about. [Accessed: 06-Oct-2016].

[14] W. M. Kappers, "Poll Everywhere! Even in the classroom: An investigation into the impact of using PollEverywhere in a large-lecture classroom," in 121 st ASEE Annual Conference and Exposition, 2014.
[15] R. GRÉGORY, "How technology breeds innovation in the educational systems," 2013. [Online]. Available: https://www.pentalog.com/blog/itservices/socrative-startup-boston-usa/. [Accessed: 28-Sep-2016].

[16] M. F. Tretinjak, A. Bednjanec, and M. Tretinjak, "Interactive teaching with Socrative," in 38th International Convention on Information and Communication Technology, Electronics and Microelectronics, MIPRO 2015 - Proceedings, 2015, no. May, pp. 848-851.

[17] D. M. Coca, "Software Socrative and smartphones as tools for implementation of basic processes of active physics learning in classroom : An initial feasibility study with prospective teachers," Eur. J Phys. Educ., vol. 4, no. 2, pp. 17-28, 2013.

[18] P. Wash, "Taking advantage of mobile devices: Using Socrative in the classroom," J. Teach. Learn. with Technol., vol. 3, no. 1, pp. 99-101, 2014.

[19] F. H. Altaany and K. A. Alsoudani, "Impact of using socrative for student in Irbid national university," in Proceeding of the 3rd Global Summit on Education GSE 2015, 2015, no. March, pp. 223-230.

[20] A. Ooms, T. Linsey, M. Webb, and A. Panayiotidis, "The in-classroom use of mobile technologies to support diagnostic and formative assessment and feedback," in 7th London International Scholarship of Teaching and Learning Conference, 2008, p. 9.

[21] J. Stuart and R. J. D. Rutherford, "Medical student concentration during lectures," Lancet, vol. 312, no. 8088, pp. 514-516, 1978.

[22] C. Viegas, G. Alves, and N. Lima, "Formative assessment diversity to foster students engagement," 2015 Int. Conf. Interact. Collab. Learn., no. September, pp. 929-935, 2015.

[23] D. Malandrino, I. Manno, G. Palmieri, V. Scarano, and G. Filatrella, "How quiz-based tools can improve students' engagement and participation in the classroom," in 2014 International Conference on Collaboration Technologies and Systems (CTS), 2014, pp. 379-386.

[24] G. Sprint and D. Cook, "Enhancing the CS1 student experience with gamification," in ISEC 2015 - 5th IEEE Integrated STEM Education Conference, 2015, pp. 94-99.

[25] B. Herbert, D. Charles, A. Moore, and T. Charles, "An investigation of gamification typologies for enhancing learner motivation," in 2014 International Conference on Interactive Technologies and Games ( iTAG), 2014, pp. 71-78.

[26] A. Bartel and G. Hagel, "Engaging students with a mobile game-based learning system in university education," in Global Engineering Education Conference (EDUCON), 2014 IEEE, 2014, pp. 957-960.

[27] C. Jacobs, M. Wilson, and C. Barker, "Using the latest developments in mobile technology to improve students' engagement with assessment feedback," in 2015 International Conference on Interactive Mobile Communication Technologies and Learning (IMCL), 2015, no. November, pp. 124-126.

[28] M. Price, K. Handley, J. Millar, and B. O’Donovan, "Feedback : all that effort, but what is the effect?," Assess. Eval. High. Educ., vol. 35, no. 3, pp. 277-289, 2010.

[29] H. J. Parkin, S. Hepplestone, G. Holden, B. Irwin, L. Thorpe, and S. H. Helen J. Parkin Graham Holden, Brian Irwin and Louise Thorpe, "A role for technology in enhancing students' engagement with feedback," Assess. Eval. High. Educ., vol. 37, no. 8, pp. 963-973, 2012. 